\title{
Effect of work-hour restriction on operative experience in cardiothoracic surgical residency training
}

\author{
Rafe C. Connors, MD, ${ }^{a}$ John R. Doty, MD, ${ }^{a}$ David A. Bull, MD, ${ }^{a}$ Heidi T. May, ${ }^{b}$ David A. Fullerton, MD, ${ }^{c}$ and \\ Robert C. Robbins, $\mathrm{MD}^{\mathrm{d}}$
}

\begin{abstract}
Objective: Resident work-hour regulations were instituted to improve patient care during resident training. Although initial data have not shown the intended benefit of limiting resident work hours, concern has developed as to whether resident operative experience has significantly decreased since instituting the work-hour restrictions.
\end{abstract}

\begin{abstract}
Methods: Resident operative logs were reviewed for 3 training institutions in the western United States for residents graduating in the years 1999-2007. Residents were divided into pre-work-hour restriction (1999-2002) and post-work-hour restriction (2003-2007) groups. Thoracic, cardiac, and all combined cases were reviewed separately for all residents at yearly intervals. Statistical analysis was subsequently conducted.

Results: A total of 37 residents were identified from 3 different programs over the study period. Thoracic cases were lower during the first year of training but increased in the second and third years of training after work-hour restrictions (78 vs 42, 65 vs 72, and 102 vs $138 ; P=.17, P=.59$, and $P=.11$, respectively). Cardiac cases were substantially lower during each year of training after work-hour restrictions (190 vs 153,154 vs 108 , and 116 vs $76 ; P=0.15, P<.0001$, and $P=.001$, respectively). Overall total cases were also lower over all years of residency after work-hour restrictions ( 251 vs 195, 219 vs 187, and 234 vs 214; $P=.03, P=.049$, and $P=.59$, respectively).

Conclusions: The overall volume of thoracic surgery cases was not significantly different after the implementation of the 80-hour work-week restriction. The total number of cardiac cases logged was substantially less during the same time period, and therefore as a result, the total number of cases performed after the implementation of the work-hour restrictions was also reduced. Although recent data have not shown an improvement in patient outcomes after restriction of resident work hours, we speculate that in a time of increasingly complex cases, reduction in resident case volumes caused by work-hour restrictions and decreasing cardiac cases might lead to inadequate operative experience.
\end{abstract}

In 2003, the Accreditation Council for Graduate Medical Education implemented the regulation of resident work hours (Table 1). ${ }^{1}$ These regulations were developed amid concerns about resident fatigue and lack of supervision on medical errors and the possible effects on resident education. ${ }^{2,3}$ Mandatory implementation of these work-hour restrictions has necessitated significant modifications in subspecialty training programs.

A central concept of work-hour restriction is the maintenance of educational opportunities and clinical experiences. In a surgical training environment, reduction of work hours can result in fewer operations performed by an individual resident and reduced or inadequate exposure to the full range of surgical procedures. ${ }^{4-10}$ To explore these issues, we examined the operative experience of 3 university-based train-

From the University of Utah Affiliated Hospitals, Salt Lake City, UT'; Intermountain Medical Center, Murray, UT ${ }^{\mathrm{b}}$; University of Colorado, Aurora, $\mathrm{Co}^{\mathrm{c}}$; Stanford University, Stanford, Calif. ${ }^{\text {d }}$

Read at the Thirty-fourth Annual Meeting of the Western Thoracic Surgical Association, Kona, Hawaii, June 25-28, 2008.

Received for publication June 28, 2008; revisions received Oct 30, 2008; accepted for publication Nov 24, 2008.

Address for reprints: John R. Doty, MD, Division of Cardiovascular and Thoracic Surgery, Eccles Outpatient Center, Suite 600, Intermountain Medical Center,

Murray, UT 84157 (E-mail: john.doty@intermountainmail.org).

J Thorac Cardiovasc Surg 2009;137:710-3

$0022-5223 / \$ 36.00$

Copyright (c) 2009 by The American Association for Thoracic Surgery

doi:10.1016/j.jtcvs.2008.11.038 ing programs in cardiothoracic surgery, comparing the prework-hour restriction period with the post-work-hour restriction period.

\section{MATERIALS AND METHODS}

After obtaining approval from our institutional review board, program directors from 3 university-based training institutions were selected for participation. Operative logs from graduating residents at the University of Utah Affiliated Hospitals, University of Colorado Affiliated Hospitals, and Stanford University Affiliated Hospitals were obtained with exclusion of any individual resident-identifying data. These logs spanned the years 1999-2007 for all residents enrolled in cardiovascular and thoracic training. Data were organized and grouped by category, which is consistent with the outlines established by the American Board of Thoracic Surgery for graduating residents (Table 2).

Residents and their respective cases were then divided into a pre-workhour restriction group (1999-2002) and a post-work-hour restriction group (2003-2007). Thoracic, cardiac, congenital, and all combined cases were reviewed separately for residents at yearly intervals, as was the total number of cases completed during their time in training. Comparisons were made directly across individual categories, as well as for the entire operative experience. Statistics were conducted by our department statistician using SPSS software (version 15.0; SPSS, Inc, Chicago, Ill). Standard descriptive statistics and mixed-model analysis were applied to explore potential differences in total case volumes and major operation categories.

\section{RESULTS}

A total of 37 residents were identified from the training programs over the study period. Twenty-five of the 37 


\section{Abbreviation and Acronym \\ ABSITE $=$ American Board of Surgery \\ In-Training Examination}

residents were included in the post-work-hour restriction group, and the other 12 residents composed the pre-workhour group. Some of the data in the early years of the study were incomplete, and we therefore eliminated any resident case $\log$ with incomplete data. The 2-year program remained at 2 years and the 3 -year programs remained at 3 years throughout the study period. The number of residents taken per year did not change during the time of our study for any of the programs.

Comparison of the average number of cardiac cases completed during each of the 3 years of training demonstrated a significant reduction in cases completed during each of the 3 years of training (Table 3). Comparison of the average number of thoracic cases over the 3 separate years of training showed no difference at any year of training between the pre-work-hour restriction and the post-work-hour restriction groups (Table 4). Comparing the total number of cases completed at each year in training showed a significantly decreased operative experience during both the first and second years, with a trend toward a significantly lower difference in the third year (Table 5).

Subcategory analysis demonstrated that myocardial revascularization and all other cardiac cases, such as major vascular cases, were significantly lower in the post-workhour implementation group, whereas operations for valvular heart disease, reoperative cardiac cases, and congenital cases were trending toward a significant decrease from the prework-hour and post-work-hour implementation groups (Table 6). Thoracic cases, however, showed a trend in virtually every subcategory toward an increased number of cases (Table 7).

\section{DISCUSSION}

Resident work-hour restrictions were implemented by the Accreditation Council for Graduate Medical Education because of increasing concerns about medical errors, a lack of resident supervision, and resident fatigue. ${ }^{1,3}$ Five years after the implementation of these restrictions, concerns surrounding the adequate education of residents in training have arisen. ${ }^{5,7}$ In surgical subspecialty training a core concept is the development of adequate technical skill through hands-on operative experience. Residency programs in cardiothoracic surgery must not only impart didactic knowledge from standard textbooks but also provide enough time in the operating room to develop the manual dexterity and decision-making abilities required to perform the necessary operations.
TABLE 1. Accreditation Council for Graduate Medical Education regulations as of July 1, 2003

1. Eighty-hour work week averaged over 4 weeks

2. One day in 7 free averaged over 4 weeks

3. Ten-hour time period between all daily duty periods and after in-house call

4. In-house call no more frequent than every third night averaged over 4 weeks

5. Continuous onsite duty not to exceed 24 hours with up to 6 additional hours for didactic activities, transfer care of patients, conduct outpatient clinics, and maintain continuity of medical and surgical care

This study demonstrates that the overall number of cases completed by cardiovascular and thoracic residents in the post-work-hour restriction period is significantly lower than in the pre-work-hour restriction period. The cardiac experience has been more significantly affected than the thoracic experience. Given the increasing complexity of the field of cardiothoracic surgery, the effect of this decrease on resident education and what should be done to ensure residents continue to receive adequate training before entering practice must be addressed.

Although restricting resident work hours has certainly contributed to the reduction in the number of cases completed, other variables exist that might account for the overall decreased experience for the residents. An overall decrease in the number of referrals for cardiac surgery at both the national and local levels has reduced operative volumes in general. This is compounded by the increasing number of smaller community hospitals performing cardiothoracic surgery outside of training programs, which are traditionally located at large tertiary hospitals. Additionally, more complex operations

TABLE 2. Subcategories for major cardiovascular operations according to American Board of Thoracic Surgery classification

Categories of operations performed

Thoracic

Lung total

Pneumonectomy, lobectomy, segmentectomy

Esophageal operations

Esophageal resections

Other esophagus

Mediastinum and diaphragm

VATS

Cardiac

Congenital heart disease, total

Congenital heart disease, surgeon

Congenital heart disease, first assist

Valvular heart disease

Myocardial revascularization

Pacemaker

Reoperations

Other adult cardiac (eg, aortic dissections)

VATS, Video-assisted thoracoscopic surgery. 
TABLE 3. Average number of cardiac operations performed during each year of residency

\begin{tabular}{lccc}
\hline & Before restriction & After restriction & $\boldsymbol{P}$ value \\
\hline Cardiac, year 1 & 190.0 & 152.9 & .15 \\
Cardiac, year 2 & 153.6 & 108.2 & $<.0001$ \\
Cardiac, year 3 & 115.5 & 74.5 & .001 \\
\hline
\end{tabular}

and increased scrutiny over outcomes might reduce opportunities for residents to perform cases as the surgeon. Work-hour restrictions and reduced operative experience during general surgical residency might further delay an individual resident's opportunity to attain adequate technical ability during cardiothoracic surgical training.

Regardless of the reasons for the decrease in the number of cases completed, the issue remains as to the effects this will have on resident training and education. The field of cardiothoracic surgery has become more complex, with a continually expanding knowledge base requirement. Increased technical skill will be mandatory for the more technically challenging high-risk cases that have become a routine part of cardiac surgery. With decreased exposure to perioperative management and operative cases, concern exists as to whether residents are adequately prepared to enter clinical practice.

Competency and adequate clinical exposure are difficult factors to measure. In-service training examination scores and national board scores are the only objective means currently available to reflect how an individual resident is progressing. Several studies examining general surgery American Board of Surgery In-Training Examination (ABSITE) scores since the work-hour reform have produced mixed results. Barden and colleagues ${ }^{11}$ found that after reducing work hours from a mean of 100.4 hours per week to 86.3 hours per week, the average ABSITE scores significantly increased. de Virglio and associates ${ }^{12}$ also evaluated test scores after decreasing on-call schedules from an average of every 4.8 nights to every 6.4 nights. Despite this on-call reduction, there was no statistical difference in the mean ABSITE scores or the first-time pass rate on the American Board of Surgery qualifying and certifying examinations. ${ }^{12}$ No studies have looked at in-service or board examination scores specifically for cardiothoracic surgery residents.

Because work-hour restrictions are currently mandatory, a solution to this developing problem must be sought to

TABLE 4. Average number of thoracic operations performed during each year of residency

\begin{tabular}{lccc}
\hline & Before restriction & After restriction & $\boldsymbol{P}$ value \\
\hline Thoracic, year 1 & 78.0 & 42.3 & .17 \\
Thoracic, year 2 & 65.0 & 71.8 & .59 \\
Thoracic, year 3 & 101.8 & 139.3 & .11 \\
\hline
\end{tabular}

TABLE 5. Average number of total cases performed during each year of residency

\begin{tabular}{lccc}
\hline & Before restriction & After restriction & $\boldsymbol{P}$ value \\
\hline Total cases, year 1 & 251.1 & 195.2 & .03 \\
Total cases, year 2 & 218.5 & 187.4 & .049 \\
Total cases, year 3 & 234.6 & 213.8 & .59 \\
\hline
\end{tabular}

avoid an even further decrease in resident education. One solution is to extend the length of training to accommodate for the reduction in time spent on a weekly basis. This would eventually provide an accumulated exposure to operative cases and clinical medicine but might deter residents from choosing specialties that already require 7 to 10 years to complete. $^{13-15}$

A second possibility is the more widespread development of a tracked system decreasing the amount of time spent in general surgical training and increasing the time spent in cardiothoracic surgical training. This would require significant revision to general surgical training programs across the country. Such focused training approaches have already occurred within cardiothoracic training in some programs, allowing the resident to choose either a cardiac or a thoracic track. In our study we found that esophageal resections, other esophageal operations, and video-assisted thoracoscopic cases all increased significantly from the pre-work-hour restriction period to the post-work-hour restriction period. The number of pulmonary resections, including pneumonectomy, lobectomy, and segmentectomy, was unchanged. This can be explained in part by the increased number of residents who have a dedicated interest in pursuing careers in thoracic surgery only, thus leading to an increased emphasis in those fields.

Similar approaches can be found in both congenital heart and transplantation surgery, in which completion of additional fellowship years is necessary to achieve various operative requirements. Another measure might be the establishment of separate board certifications for these subspecialized areas. In the era of an increasing required knowledge base, as well as technically more challenging cases,

TABLE 6. Mean number of cardiac-related cases performed during all years of residency according to ABTS subcategory

\begin{tabular}{lccc}
\hline & $\begin{array}{c}\text { Before } \\
\text { restriction }\end{array}$ & $\begin{array}{c}\text { After } \\
\text { restriction }\end{array}$ & $\begin{array}{c}\boldsymbol{P} \\
\text { value }\end{array}$ \\
\hline Congenital, total & 84.8 & 93.2 & .61 \\
Congenital & 63.6 & 49.3 & .17 \\
CHD, first assistant & 33.4 & 44.0 & .45 \\
Valvular heart disease & 87.7 & 77.8 & .45 \\
Myocardial revascularization (CABG) & 148.1 & 110.6 & .003 \\
Reoperations & 17.2 & 13.3 & .43 \\
Other adult cardiac & 115.0 & 77.8 & .09 \\
\hline ABTS, American Board of Thoracic Surgery; $C H D$, congenital heart disease; $C A B G$, \\
coronary artery bypass grafting.
\end{tabular}


TABLE 7. Mean number of thoracic-related cases performed during all years of residency according to ABTS subcategory

\begin{tabular}{lccc}
\hline & $\begin{array}{c}\text { Before } \\
\text { restriction }\end{array}$ & $\begin{array}{c}\text { After } \\
\text { restriction }\end{array}$ & $\begin{array}{c}\boldsymbol{P} \\
\text { value }\end{array}$ \\
\hline Lung (pneumonectomy, & 47.1 & 47.1 & .99 \\
$\quad$ lobectomy, segmentectomy) & & & \\
Other lung & 95.4 & 120.4 & .31 \\
Esophageal operations & 15.6 & 18.5 & .27 \\
Esophageal resections & 9.5 & 13.1 & .20 \\
VATS & 36.9 & 47.4 & .42 \\
\hline
\end{tabular}

ABTS, American Board of Thoracic Surgery; VATS, video-assisted thoracoscopic surgery.

requirement of additional fellowship years and separate board requirements might be an important part of the solution for residents to gain further knowledge and training before entering practice.

Regardless of the underlying causes of the reduced operative experience, residents at these 3 programs are not receiving the same exposure to complex cardiothoracic operations in the post-work-hour restriction period. Although there have been no studies performed to evaluate resident competency at the completion of their training, reduction in resident operative experience because of work-hour restrictions and decreasing cardiac cases might lead to inadequately trained residents. The field of cardiothoracic surgery must be willing to find solutions that will reverse this trend and train our residents to perform at the highest level after completion of residency.

\section{References}

1. Accreditation Council for Graduate Medical Education. Report of the ACGME work group on resident duty hours [ACGME Web site]. Available at: http:// www.acgme.org/dutyhours/wkgroupreport611.pdf. Accessed June 2008.

2. Zinner MJ. Surgical residencies: are we still attracting the best and the brightest? Bull Am Coll Surg. 2002;87:20-5

3. Niederee MJ, Knudtson JL, Byrnes MC, Helmer SD, Smith RS. A survey of residents and faculty regarding work hour limitations in surgical training programs. Arch Surg. 2003;138:663-71.

4. Mendoza KA, Britt LD. Resident operative experience during the transition to work-hour reform. Arch Surg. 2005;140:137-47.

5. Carlin AM, Gasevic E, Shepard AD. Effect of the 80-hour work week on resident operative experience in general surgery. Am J Surg. 2007;193:326-30.

6. Tran J, Lewis R, de Virgilio C. The effect of the 80-hour work week on general surgery resident operative case volume. Am Surg. 2006;72:924-8.

7. Jarman BT, Miller MR, Brown RS, Armen SB, Bozaan AG, Ho GT, et al. The 80hour work week: will we have less-experienced graduating surgeons? Curr Surg. 2004;61:612-5.

8. Naylor RA, Rege RV, Valentine RJ. Do resident duty hour restrictions reduce technical complications of emergency laparoscopic cholecystectomy? $J$ Am Coll Surg. 2005;201:724-31.

9. Ferguson CM, Kellogg KC, Hutter MM, Warshaw AL. Effect of work-hour reforms on operative case volume of surgical residents. Curr Surg. 2005;62:535-8.

10. Feanny MA, Scott BG, Mattox KL, Hirshberg A. Impact of the 80-hour work week on resident emergency operative experience. Am J Surg. 2005;190:947-9.

11. Barden CB, Specht MC, McCarter MD, Daly JM, Fahey TJ 3rd. Effects of limited work hours on surgical training. J Am Coll Surg. 2002;195:531-8.

12. de Virgilio C, Yaghoubian A, Lewis RJ, Stabile BE, Putnam BA. The 80-hour resident workweek does not adversely affect patient outcomes or resident education. Curr Surg. 2006;63:435-9.

13. Gelfand DV, Podnos YD, Wilson SE, Cooke J, Williams RA. Choosing general surgery: insights into career choices of current medical students. Arch Surg. 2002; 137:941-7.

14. Bland KI, Isaacs G. Contemporary trends in student selection of medical specialties: the potential impact on general surgery. Arch Surg. 2002;137:259-67.

15. Leibrandt TJ, Pezzi CM, Fassler SA, Reilly EF, Morris JB. Has the 80-hour work week had an impact on voluntary attrition in surgery residency programs. $J$ Am Coll Surg. 2006;202:340-4 